\title{
THE ICCA JOURNAL AWARD
}

\author{
The Board of the ICCA
}

For the period April 1, 1992 to March 31, 1993, the ICCA Journal Award for the best paper in this Journal by a first-time author has been awarded to Peter Jansen for his article: KQKR: Awareness of a Fallible Opponent, ICCA Journal, Vol. 15, No. 3, pp. 111-131. The jury consisted of T.A. Marsland, D.N.L. Levy, D.F. Beal, and H.J. van den Herik (see ICCA Journal, Vol. 16, No. 4, pp. 218-219). As an intrinsic part of the Award, a brief scientific biography of the winner is published below.

\section{PETER JANSEN: A SCIENTIFIC BIOGRAPHY}

Peter Jansen received the degree of $\mathrm{Ph} . \mathrm{D}$. in Computer Science from Carnegie-Mellon University in September 1992. His thesis, supervised by Professor H.A. Simon, was entitled Using Knowledge about the Opponent in Game-Tree Search (Jansen, 1992a). The Award-winning article "Awareness of a Fallible Opponent" (Jansen, 1992b) was based on this doctoral dissertation.

Computer Chess has been a main research interest ever since he became involved (1987-1991) in the Deep Thought team. This involvement allowed him to follow and analyse games and matches between top players (humans and computers) very closely, such as the Candidate Match between Spraggett and Yusupov in January 1989 (Jansen and Schaeffer, 1990). This led to a study of how the performance of certain search algorithms is influenced by some characteristics of the domain, for instance, in which part of the domains certain agents (e.g., human players) are most likely to make mistakes (Jansen, 1990).

Dr. Jansen is currently with the Center for Machine Translation at Carnegie-Mellon University. Apart from Computer Chess and the Theory of Games, his research interests include Machine Translation, NaturalLanguage Processing and Computational Linguistics.

Publications in computer chess:

Jansen, P.J. and Schaeffer, J. (1990). Seconding a Grandmaster. ICCA Journal, Vol 13, No. 1, pp. 29-34.

Jansen, P.J. (1990). Problematic Positions and Speculative Play. Computers, Chess, and Cognition (eds. T.A. Marsland and J. Schaeffer), pp. 169-181. Springer-Verlag, New York. ISBN 0-387-97415-6.

Jansen, P.J. (1992a). Using Knowledge about the Opponent in Game-Tree Search. Ph.D. Thesis, CarnegieMellon University, Pittsburgh, PA.

Jansen, P.J. (1992b). KQKR: Awareness of a Fallible Opponent. ICCA Journal, Vol 15, No. 3, pp. 111-132.

Jansen, P.J. (1992c). KQKR: Assessing the Utility of Heuristics. ICCA Journal, Vol 15, No. 4, pp. 179-192.

Jansen, P.J. (1993). KQKR: Speculatively Thwarting a Human Opponent. ICCA Journal, Vol 16, No. 1, pp. 3-18.

Gobet, F. and Jansen, P.J. (1994). Towards a Chess Program Based on a Model of Human Memory. Advances in Computer Chess 7 (eds. H.J. van den Herik, I.S. Herschberg and J.W.H.M. Uiterwijk), pp. 3561. University of Limburg, Maastricht, The Netherlands. ISBN 90-6216-1014. 